\title{
The alternative Pharaoh approach: stingless bees mummify beetle parasites alive
}

\author{
Mark K. Greco • Dorothee Hoffmann • Anne Dollin • \\ Michael Duncan • Robert Spooner-Hart • \\ Peter Neumann
}

Received: 5 December 2008 /Revised: 30 October 2009/Accepted: 19 November 2009/Published online: 9 December 2009

(C) Springer-Verlag 2009

\begin{abstract}
Workers from social insect colonies use different defence strategies to combat invaders. Nevertheless, some parasitic species are able to bypass colony defences. In particular, some beetle nest invaders cannot be killed or removed by workers of social bees, thus creating the need for alternative social defence strategies to ensure colony survival. Here we show, using diagnostic radioentomology, that stingless bee workers (Trigona carbonaria) immediately mummify invading
\end{abstract}

M. K. Greco $(\bowtie) \cdot$ P. Neumann

Swiss Bee Research Centre,

Agroscope Liebefeld-Posieux Research Station ALP,

CH-3033 Bern, Switzerland

e-mail: mark.greco@alp.admin.ch

M. K. Greco • M. Duncan • R. Spooner-Hart

Centre for Plant and Food Science, School of Natural Sciences,

University of Western Sydney,

Richmond, NSW 1797, Australia

D. Hoffmann

Department of Zoology,

Martin-Luther-Universität Halle-Wittenberg,

Hoher Weg 4,

06099 Halle, Saale, Germany

A. Dollin

Australian Native Bee Research Centre,

North Richmond, NSW, Australia

P. Neumann

Department of Zoology and Entomology, Rhodes University, 61440 Grahamstown, Republic of South Africa

D. Hoffmann

KU Leuven, Laboratory of Aquatic

Ecology and Evolutionary Biology,

Charles Deberiotstraat 32 - bus 2439,

3000 Leuven, Belgium adult small hive beetles (Aethina tumida) alive by coating them with a mixture of resin, wax and mud, thereby preventing severe damage to the colony. In sharp contrast to the responses of honeybee and bumblebee colonies, the rapid live mummification strategy of $T$. carbonaria effectively prevents beetle advancements and removes their ability to reproduce. The convergent evolution of mummification in stingless bees and encapsulation in honeybees is another striking example of co-evolution between insect societies and their parasites.

Keywords Stingless bee $\cdot$ Diagnostic radioentomology Beetles · Parasites

\section{Introduction}

Social insects live in colonies exploited by parasites which feed on stored food or brood (Roubik 1989; Schmid-Hempel 1998), generating the need for efficient defence mechanisms (Breed 2003; Breed et al. 2004, 2007; Lehmberg et al. 2008). Parasitizing beetles pose particular difficulties for social insects because their exoskeletons protect them from direct primary defence strategies such as biting or stinging. The small hive beetle (SHB), Aethina tumida (Coleoptera: Nitidulidae), is such a parasite. It scavenges honeybee (Apis mellifera) colonies endemic to sub-Saharan Africa (Lundie 1940; El-Niweiri et al. 2008; Neumann and Ellis 2008) and has become an invasive species with established populations in North America and Australia (Neumann and Ellis 2008). SHB invade nests to feed on brood, stored food or dead bees (Lundie 1940; Schmolke 1974; Neumann and Elzen 2004; Spiewok and Neumann 2006a) often causing complete destruction of nests, especially from their feeding larval stages (Neumann and Elzen 2004). Although adult SHB are 
vigorously attacked by workers (Elzen et al. 2001), they usually bypass the bees' nest entrance defences and remain difficult to kill or eject due to their hard exoskeleton and defence behaviours (Neumann et al. 2001; Neumann and Elzen 2004). Cape honeybees, A. m. capensis, display alternative defence mechanisms by encapsulating small hive beetles in tombs made from resin (Neumann et al. 2001; Ellis et al. 2003). Despite the lack of co-evolution between host and parasite, European honeybees also encapsulate small hive beetles (Ellis et al. 2003) suggesting that encapsulation appears to be part of the general alternative defence of honeybee colonies.

Recent evidence suggests that SHB also parasitize colonies of bumblebees (Bombus impatiens, Spiewok and Neumann 2006b; Hoffmann et al. 2008) and stingless bees (Trigona carbonaria; Anne Dollin, personal observations). Analogous to propolis usage by honeybees, stingless bees use batumen to seal nest cavities (Michener 1961). Therefore, we hypothesised that stingless bees may show an analogue to honeybee social encapsulation of SHB, by restricting parasite advancement and reproduction. We tested this hypothesis by observing experimental infestations of $T$. carbonaria colonies using diagnostic radioentomology.

\section{Materials and methods}

Laboratory reared (Muerrle and Neumann 2004) adult SHB with $\mathrm{BaSO}_{4}$-marked elytra, were introduced to entrances of five $T$. carbonaria hives, $N=10$ beetles per hive, via transparent plastic observation tubes (Hoffmann et al. 2008). Beetle-bee interactions at hive entrances were visually observed $(5 \mathrm{~min})$. To non-invasively monitor movements of beetles that managed to bypass guards, hives were CT-scanned at 5-min intervals for $90 \mathrm{~min}$ in a human body scanner (GE HiSpeed 64 Slice, General Electric Company; Greco et al. 2006). Beetle distributions in hives were assessed using BeeView 3D rendering software (Disect Systems Ltd; Suffolk, UK). Twodimensional images were created to enable precise measurements of vector distances of SHB from hive entrances with on-screen linear callipers (Greco et al. 2005 ) and $3 \mathrm{D}$ images were generated to provide visual spatial representation of SHB with respect to hive structures. One hive was randomly selected after scanning and snap frozen with liquid nitrogen for visual screening to compare SHB positions with respect to scanned images. We applied a linear mixed model in a block design, with "colonies" as five random blocks and "time" as a fixed factor with ten observations of distances for each time point, to assess any "colony" or "time" effects (it was not possible to fit a "repeated measurements' model because beetles were not identified as individuals):

$Y_{i j k}=\mu+C_{i}+t_{j}+\varepsilon_{i j k}$

where,

$Y_{i j k} \quad$ was $k$ th distance measured in colony $i$ at time $\mathrm{j}$

$\mu \quad$ was global mean

$C_{i} \quad$ was effect of colony $I, I=1,2, \ldots, 5$ (random)

$t_{j} \quad$ was effect of time $j, j=0,5,10$ (fixed)

$\varepsilon_{i j k} \quad$ was the random error of the $k$ th observation in colony $i$ at time $j, k=1,2, \ldots, 10$

$\mathrm{C}_{\mathrm{i}} \sim \mathrm{N}\left(0, \sigma^{2}\right)$

$\varepsilon_{\mathrm{ijk}} \sim \mathrm{N}\left(0, \sigma^{2}\right)$.

We also tested a model of diffusion (random walk) to assess whether SHB were prevented from normal random walk distributions. If we assume the beetles to move randomly and free of attacks then the model of "random walk" can be helpful for modelling the distribution of measured distances at a given time. This is equivalent to the process of diffusion of a solute in a solvent and can be checked statistically by a Chi-square goodness-of-fit test with the normal distribution of the measured distances. For all statistical analyses we used Systat Software Inc, Chicago, IL 60606, USA.

\section{Results}

Upon introduction of SHB, visual observations confirmed that workers from all hives immediately attacked and coated introduced beetles with batumen. The attacks by workers (Fig. 1a) caused most beetles to remain motionless in the turtle defence posture (Neumann et al. 2001). When not attacked, beetles were observed moving further into the hive. However, most $T$. carbonaria bees continuously attacked, thereby keeping the SHB in the turtle defence posture until mummified (Fig. 1b). Although three beetles (mummified on the spot, $<5 \mathrm{~mm}$ from hive entrance) did not progress, $47 \mathrm{did}$ (Table 1). In one hive, two SHB reached a distance of $170 \mathrm{~mm}$ from the entrance, just below the brood (Fig. 2a). All SHB advancements ceased within $10 \mathrm{~min}$ of introduction (Fig. 2b). After 90 min, mean distance from hive entrances was $64 \pm 51 \mathrm{~mm}$ (maximum distance $=170 \mathrm{~mm}$, minimum distance $=2 \mathrm{~mm}, N=50$ measurements). The linear mixed model showed that there was a significant "time" and "colony" effect on beetle distribution, $p<0.05$ and $<0.001$ 


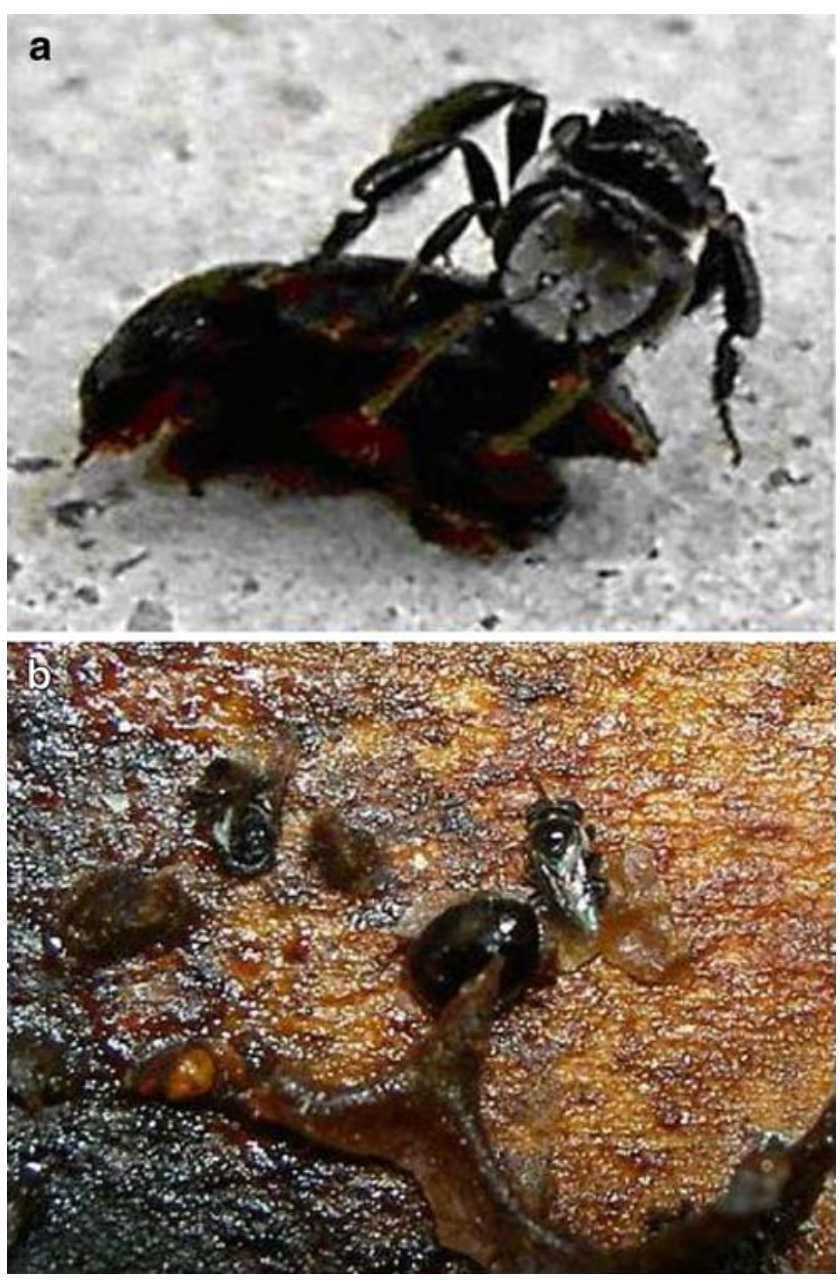

Fig. 1 A T. carbonaria worker mummifies a live small hive beetle by coating it with batumen on the beetle's elytra and legs (a) and visual confirmation of a mummified beetle on the floor of a T. carbonaria hive (b)

respectively. Beetles travelled furthest between time 0 and 5 min and travelled least in colony 1 and furthest in colony 4. At "time" 0 to $5 \mathrm{~min}$ the model for diffusion or "random walk" was accepted, $\mathrm{Chi}^{2}=4.12$, $p=0.53$ ( $5 \mathrm{~min}), \mathrm{df}=5$, showing that beetles were able to disperse between 0 and $5 \mathrm{~min}$. At "time" $10 \mathrm{~min}$ the model for diffusion or "random walk" was rejected, $\mathrm{Chi}^{2}=24.11, p<0.001$, showing that beetles were unable to disperse freely between 5 and $10 \mathrm{~min}$. Dissection of the snap frozen hive confirmed positions and batumen coatings which corresponded to previously scanned images (Fig. 2c and d).

\section{Discussion}

Our data clearly show that $T$. carbonaria workers efficiently prevented SHB advancements and subsequent

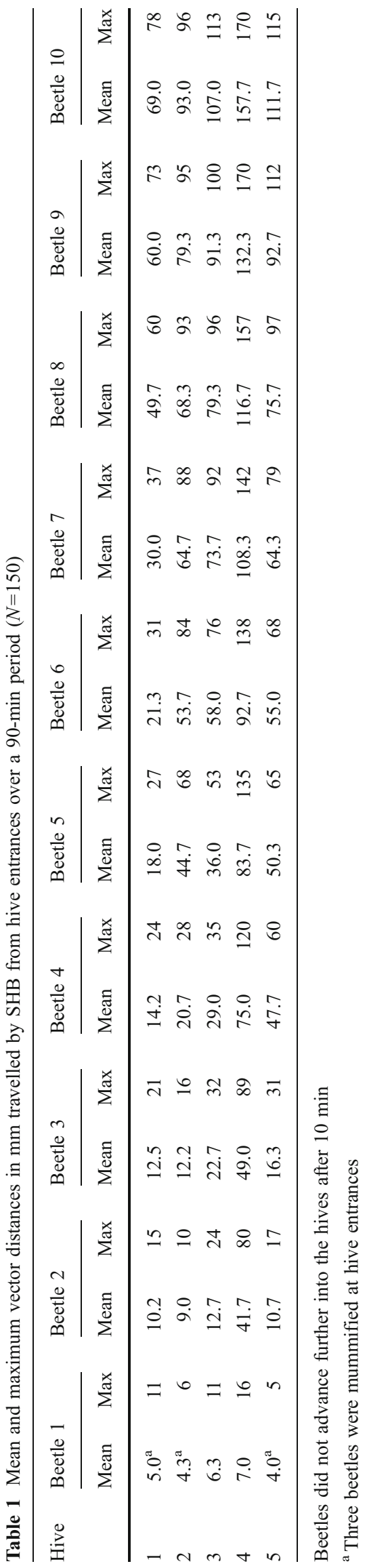



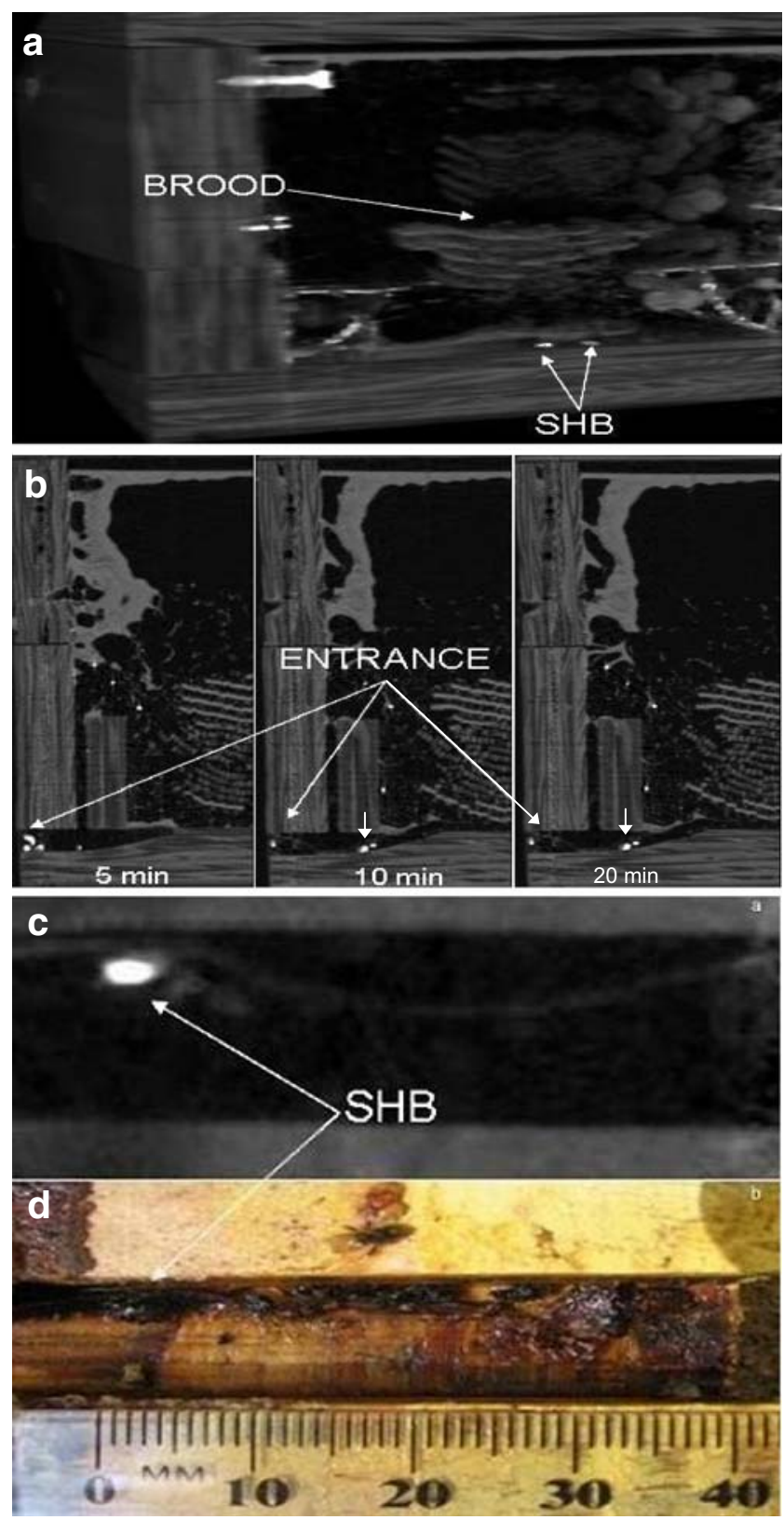

Fig. 2 Live mummification of adult small hive beetles in $T$. carbonaria hives: a 3D CT image of $T$. carbonaria brood (single arrow) and two small hive beetles below brood (double arrows); b 2D CT image of small hive beetles (short arrows) in entrance of T. carbonaria hive demonstrating no change in position after $10 \mathrm{~min}$; c 2D CT image, taken $90 \mathrm{~min}$ after introduction to the hive, of an adult small hive beetle which has been mummified by guards of T. carbonaria and d visual confirmation of the beetle's position and evidence of the batumen coating, applied by guard bees, which prevented further movements by the beetle

reproduction within 10 min by coating them with batumen directly on their bodies. Here we adopt the term mummification because honeybees do not coat live beetles directly with propolis but instead confine them in prisons (Neumann et al. 2001; Ellis et al. 2003). Mummification by stingless bees appears to be more effective than social encapsulation by honeybees because in sharp contrast to A. mellifera (Neumann et al. 2001), all introduced SHB were affected.

A number of native nitidulid species has been reported in Trigona nests (Brachypeplus auritus, Brachypeplus basalis Lea 1910; Carpophilus planatus Lea 1912, Brachypeplus planus and Brachypeplus meyricki Rayment 1935). As with Cychramus luteus in A. mellifera colonies (Neumann and Ritter 2004), these endemic beetles do not normally harm the colony (personal observations $\mathrm{AD}$ ), nevertheless mummification may have evolved to prevent them and other invaders from reproducing in the nest. Social encapsulation of live intruders in wax or propolis confinements has been described from A. mellifera (Neumann et al. 2001). Likewise, Bombus and stingless bees have been reported to coat intruders with resin (Kerr and Lello 1962; Michener 1974; Nates and Cepeda 1983; Roubik 1989; Betz and Koelsch 2004). However, to our knowledge, this is the first report of mummification of live nest intruders in colonies of social bees.

When SHB beetles adopt the turtle defence posture most honeybee workers eventually leave the beetles, which then scurry into hiding or progress further into the colony (Neumann et al. 2001). In contrast, T. carbonaria workers continuously attack, thereby keeping the SHB in the turtle defence posture, which enables other workers to mummify live beetles with batumen. Indeed, our data suggest that many beetles are immobilised between 5 and $10 \mathrm{~min}$, thus, unable to move unhindered according to a model assuming random walk. It appears that the combination of continuous attacks and quick recruitment of mummifying workers underlies this efficient alternative defence mechanism of $T$. carbonaria. There have, however, been reports of heat-stressed $T$. carbonaria colonies being destroyed by small hive beetles (MG, personal observations), suggesting that this invasive species may still pose some threat to native pollinators.

In conclusion, a single stingless bee worker is not able to eject or kill beetle parasites unaided. Only a team with individuals performing specific tasks (e.g. wrestling or gluing) can overcome parasite advancements. Live encapsulation of SHB by stingless bees has probably evolved as an alternative defence mechanism to prevent successful reproduction of nest parasites. It is evidently effective, because beetles are quickly immobilised, preventing successful reproduction. This seems especially important in light of the high reproductive potential and high infestation numbers of SHB (Spiewok et al. 2007). The convergent evolution of live mummification of nest parasites in stingless bees and social encapsulation in honeybees is another striking example of evolution between insect societies and their parasites. 
Acknowledgements We thank Macarthur Diagnostic Imaging for donating time on the CT scanner and for use of their Campbelltown facility.

\section{References}

Betz O, Koelsch G (2004) The role of adhesion in prey capture and predator defence in arthropods. Arthropod Structure \& Development 33:3-30

Breed MD (2003) Nestmate recognition assays as a tool for population and ecological studies in eusocial insects: a review. J Kans Entomol Soc 76:539-550

Breed MD, Guzman-Novoa E, Hunt GJ (2004) Defensive behaviour of honey bees: organization, genetics, and comparisons with other bees. Annu Rev Entomol 49:271-298

Breed MD, Deng XB, Buchwald R (2007) Comparative nestmate recognition in Asian honey bees, Apis florea, Apis andreniformis, Apis dorsata, and Apis cerana. Apidologie 38(5):411-418

Ellis JD, Hepburn HR, Ellis AM, Elzen PJ (2003) Social encapsulation of the small hive beetle (Aethina tumida Murray) by European honeybees (Apis mellifera L.). Insect Soc 50:286291

El-Niweiri MAA, El-Sarrage MS, Neumann P (2008) Filling the Sudan gap: the northern most natural distribution limit of small hive beetles. Journal of Apicultural Research and Bee World 47(3):183-184

Elzen PJ, Baxter JR, Neumann P, Solbrig A, Pirk CWW, Hepburn HR, Westervelt D, Randall C (2001) Behaviour of African and European subspecies of Apis mellifera toward the small hive beetle, Aethina tumida. J Apic Res 40:40-41

Greco MK, Spooner-Hart R, Holford P (2005) A new technique for monitoring Trigona carbonaria nest contents, brood and activity using X-ray computerised tomography. J Apic Res 44:97-100

Greco MK, Bell M, Spooner-Hart R, Holford P (2006) X-ray computerized tomography as a new method for monitoring Amegilla holmesi nest structure, nesting behaviour and adult female activity. Entomol Exp Appl 120:71-76

Hoffmann D, Pettis JS, Neumann P (2008) Potential host shift of the small hive beetle (Aethina tumida) to bumblebee colonies (Bombus impatiens). Insectes Soc 55:153-162

Kerr WE, Lello E (1962) Sting glands in stingless bees. J N Y Entomol Soc 70:190-214

Lea AM (1910) Australian and Tasmanian Coleoptera inhabiting or resorting to the nests of ants, bees and termites. Proc R Soc Victoria [NS] 23:116-230
Lea AM (1912) Australian and Tasmanian Coleoptera inhabiting or resorting to the nests of ants, bees and termites. Proc R Soc Victoria [NS] 25(Suppl):31-78

Lehmberg L, Dworschak K, Bluethgen N (2008) Defensive behaviour and chemical deterrence against ants in the stingless bee genus Trigona (Apidae, Meliponini). J Apic Res 47:17-21

Lundie AE (1940) The small hive beetle Aethina tumida, Science Bulletin 220. Department of Agriculture and Forestry, Government Printer, Pretoria

Michener CD (1961) Observations on the nests and behaviour of Trigona in Australia and New Guinea (Hymenoptera: Apidae). Am Mus Novit 2026:1-45

Michener CD (1974) The social behaviour of the bees; A comparative study. Harvard University Press, Harvard, p 404

Muerrle TM, Neumann P (2004) Mass production of small hive beetles (Aethina tumida Murray, Coleoptera: Nitidulidae). J Apic Res 43:144-145

Nates G, Cepeda O (1983) Comportamiento defensivo en algunas especies de meliponínos. Boletín del Departamento de la Biologia de la Universidad Nacional de Colombia, Bogotá 1:65-81

Neumann P, Ellis JD (2008) The small hive beetle (Aethina tumida Murray, Coleoptera: Nitidulidae): distribution, biology and control of an invasive species. J Apic Res 47:181-183

Neumann P, Elzen PJ (2004) The biology of the small hive beetle (Aethina tumida Murray, Coleoptera: Nitidulidae): gaps in our knowledge of an invasive species. Apidologie 35:229-247

Neumann P, Ritter W (2004) A scientific note on the association of Cychramus luteus (Coleoptera: Nitidulidae) with honeybee (Apis mellifera) colonies. Apidologie 35:665-666

Neumann P, Pirk CWW, Hepburn HR, Solbrig AJ, Ratnieks FLW, Elzen PJ, Baxter JR (2001) Social encapsulation of beetle parasites by Cape honeybee colonies (Apis mellifera capensis Esch.). Naturwissenschaften 88:214-216

Rayment T (1935) A cluster of bees. The Endeavour, Sydney

Roubik DW (1989) Ecology and natural history of tropical bees. Cambridge University Press, Cambridge

Schmid-Hempel P (1998) Parasites in social insects. Princeton University Press, Princeton

Schmolke MD (1974) A study of Aethina tumida: the small hive beetle, Project Report, University of Rhodesia

Spiewok S, Neumann P (2006a) Cryptic low-level reproduction of small hive beetles in honeybee colonies. J Apic Res 45:47-48

Spiewok S, Neumann P (2006b) Infestation of commercial bumblebee (Bombus impatiens) field colonies by small hive beetles (Aethina tumida). Ecol Entomol 31:623-628

Spiewok S, Pettis JS, Duncan M, Spooner-Hart R, Westervelt D, Neumann P (2007) Small hive beetle, Aethina tumida, populations I: infestation levels of honeybee colonies, apiaries and regions. Apidologie 38:595-605 